\title{
Current and Emerging DMARDs for the Treatment of Rheumatoid Arthritis
}

\author{
Eduardo Mysler \\ Mariana Caubet \\ Ana Lizarraga \\ Organización Medica de Investigación, \\ Buenos Aires, Argentina
}

\begin{abstract}
Rheumatoid arthritis (RA) is the most prevalent form of inflammatory arthritis. It is a profoundly serious and severe disease that if it goes untreated could have severe consequences to the joints and health of the patient who carries this diagnosis. The treatment of RA has dramatically changed since the year 2000, with the discovery of the TNFis, then other biologics, and finally the JAKi. All these new medications with or without methotrexate in combination, tight control and treat to target have produced a revolution in the outcome of this disease. We reviewed and summarized the treatment options, and the most significant papers for each one of these new drugs. The reader could have a full picture with all the references of the recent publications. We also updated the biosimilar situation in RA, as well as the new drugs that will be coming to the market in the next 5 years.
\end{abstract}

Keywords: rheumatoid arthritis, DMARDs, biosimilars

\section{Introduction}

Rheumatoid arthritis (RA) is one of the most prevalent chronic inflammatory joint diseases that can lead to cartilage and bone damage as well as disability. In the last two decades, a therapeutic revolution in the treatment of RA has begun that includes treat to target strategy, tight control and new biologic and non-biologic antirheumatic drugs. With the aim to prevent structural joint damage, loss of function and maintain quality of life, patients are treated early and more aggressively.

RA is a heterogenic disease that requires the use of multiple therapies with different mode of action to achieve remission or at least low disease activity, as recommended by the EULAR guidelines and treat to target. No clear biomarker has been described that allows us to decide which drug is better for each individual patient. Two types of advance therapies are available (Table 1): bDMARDs (biological disease modifying antirheumatic drugs) which are most frequently monoclonal antibodies or receptor constructs that target a specific soluble or cell surface molecule, either a cytokine, a cytokine receptor or another cell membrane antigen. They either prevent interaction of the specific ligand with its receptor, destroy a specific cell population, or inhibit interaction between particular cell populations. They must be administered IV or SC since they are proteins. They also do not enter the cell but mediate their respective modes of action outside the cell or via the cell surface.

Target synthetic DMARDs, like the JAKi (Janus Kinase inhibitors), represent a series of intracellularly active drugs. The pathways that mediate cytokine receptor 
Table I Approved Drugs for RA Treatment

\begin{tabular}{|c|c|c|c|}
\hline Drug & Structure & Mode of Action & Pivotal Studies \\
\hline Infliximab & Chimeric monoclonal antibody & Anti TNF inhibitor & $\begin{array}{l}\text { ATTRACT Maini } 1999 \\
\text { ASPIRE St Clair } 2004 \\
\text { BEST Yvonne } 2007\end{array}$ \\
\hline Etanercept & Fusion protein & Anti TNF inhibitor & $\begin{array}{l}\text { ERA Barthon } 2000 \\
\text { COMET Emery } 2008 \\
\text { TEMPO Klareskog } 2004\end{array}$ \\
\hline Adalimumab & Human monoclonal antibody & Anti TNF inhibitor & $\begin{array}{l}\text { ARMADA Weinblatt } 2003 \\
\text { PREMIER Breedvelt } 2006 \\
\text { OPTIMA Kavanaugh } 2013\end{array}$ \\
\hline Certolizumab & Pegylated human monoclonal antibody & Anti TNF inhibitor & $\begin{array}{l}\text { RAPID I Keystone } 2008 \\
\text { RAPID } 2 \text { Smolen } 2009 \\
\text { FAST4WARD Fleischmann } 2009\end{array}$ \\
\hline Golimumab & Human monoclonal antibody & Anti TNF inhibitor & $\begin{array}{l}\text { GO BEFORE Emery } 2009 \\
\text { GO FORWARD Keystone } 2009 \\
\text { GO AFTER Smolen } 2009\end{array}$ \\
\hline Abatacep & Human fusion protein & T Cell co stimulatory inhibition (CD80/CD86) & $\begin{array}{l}\text { ABA in MTX RESISTENT PATIENTS Kremer } 2006 \\
\text { ABA in TNF REFRACTORY PATIENTS Genovese } 2005 \\
\text { ACQUIRE Genovese 2011 }\end{array}$ \\
\hline Tocilizumab & Human monoclonal antibody & Antill 6 inhibitor receptor & $\begin{array}{l}\text { TOWARD Genovese } 2008 \\
\text { RADIATE Emery } 2008 \\
\text { AMBITION Jones } 2010 \\
\text { ACT-RAY Dougados } 2013\end{array}$ \\
\hline Sarillumab & Human monoclonal antibody & Antill 6 inhibitor receptor & $\begin{array}{l}\text { SARIL-RA-MOBILITY Huizinga } 2014 \\
\text { TARGET Fleischmann } 2017\end{array}$ \\
\hline Rituximab & Chimeric monoclonal antibody & B cell depletion (anti CD20) & $\begin{array}{l}\text { DANCER Emery } 2006 \\
\text { REFLEX Cohen } 2006\end{array}$ \\
\hline Tofacitinib & Small molecule & JAKI and JAK3 inhibitor & $\begin{array}{l}\text { ORAL Start } \\
\text { ORAL Sync } \\
\text { ORAL Scan } \\
\text { ORAL Solo } \\
\text { ORAL Standard } \\
\text { ORAL Step } \\
\text { Oral Strategy }\end{array}$ \\
\hline Baricitinib & Small molecule & JAK I and JAK 2 inhibitor & $\begin{array}{l}\text { RA Begin } \\
\text { RA Beacon } \\
\text { RA Bean } \\
\text { RA Build } \\
\text { RA Beyond }\end{array}$ \\
\hline Upadacitinib & Small molecule & JAKI inhibitor & $\begin{array}{l}\text { SELECT Netx } \\
\text { SELECT Beyond } \\
\text { SELECT Monotherapy } \\
\text { SELECT Early } \\
\text { SELECT Compare } \\
\text { SELECT Choice }\end{array}$ \\
\hline Filgotinib & Small molecule & JAKI inhibitor & $\begin{array}{l}\text { FINCH I } \\
\text { FINCH } 2 \\
\text { FINCH } 3 \\
\text { FINCH } 4\end{array}$ \\
\hline
\end{tabular}


signal transduction JAKs are non-receptor tyrosine kinases associated with the cytoplasmic domain of type I and II cytokine receptors which are activated when these are engaged by their ligands; once phosphorylated, they phosphorylate signal transducers and activators of transcription (STATs) which then induce gene activation. They are oral small molecules that act intracellularly, in a reversible way, preventing the phosphorylation of JAKs. Many cytokines, such as interleukin (IL)-2, 6, 12, 15 and 23 as well as interferons use the JAK-STAT pathways, while others, such as IL-1, IL-17 and TNF, do not use JAK enzymes. JAK1, 2, 3 and TYK2 - function as dimers and once activated phosphorylate STATs, which subsequently induce gene transcription.

Actually, there are five molecular target families available as treatment options for RA: tumor necrosis factor (TNF) inhibitors, interleukin 6 (IL-6) receptor blockers, CD80/86 inhibitors, anti-CD20 and Janus kinases (JAK) inhibitors with multiple drugs for several of these mechanisms. Biosimilars (to some of these drugs) have been developed, becoming part of the rheumatologic armamentarium that needs to be considered, as they will increase access.

The goal of this review is to describe the current therapies, including recently approved anti-rheumatic agents, and to mention the ones that are in development (mainly in Phase 3) focusing on efficacy and emerging safety issues. Randomized controlled clinical trials that have been done to prove the efficacy and safety of drugs for the treatment of rheumatoid arthritis were selected from different databases (including PubMed, EULAR and ACR congresses). A specific search with words including clinical trials, head-to-head clinical trials, biologic DMARDs and synthetic DMARDs in rheumatoid arthritis. We also asked colleagues for specific trials that could have been important for the paper.

\section{The Anchor Drug: Methotrexate}

Methotrexate (MTX) remains the first choice in the treatment of rheumatoid arthritis, because it is effective in $25 \%$ of patients (remission), has an acceptable toxicity profile and low costs. In the management of early and established RA, MTX is recommended as a first-line drug by the European League Against Rheumatism (EULAR) and the American College of Rheumatology (ACR). It has shown to be effective in monotherapy and also is the basis for combination therapies. In early RA patients, starting MTX in monotherapy followed by the addition of anti TNF on MTX treatment failure at 6 months had similar outcomes (clinical and functional) compared with patients who started on a combination therapy. It is important to remember that a group of patients will achieve remission only with methotrexate monotherapy, so avoiding over-treatment should always be considered.

\section{Anti TNF Alpha Agents}

Tumor necrosis factor (TNF) is a pro-inflammatory cytokine that plays an important role in joint inflammation and contributes to joint destruction. The inhibition of TNF improves the clinical manifestations of RA and reduced radiographic progression. There are 5 biologic agents targeting the TNF approved for the treatment of RA: infliximab (INF), etanercept (ETN), adalimumab (ADA), certolizumab (CMZ) and golimumab (GLM). Several clinical trials of these compounds showed excellent efficacy on RA and an acceptable risk profile.

Infliximab was the first TNF alpha inhibitor (TNFi) developed. It is a chimeric monoclonal antibody and requires intravenous application every 4-8 weeks. Several controlled trials demonstrated the efficacy of INF for early and stablished RA. Patients receiving the combination treatment (infliximab + MTX) showed lower radiographic progression, higher remission rates and improved efficacy compared to patients receiving MTX alone.

Etanercept is a fusion protein of the soluble TNF receptor and Fc portion of immunoglobulin, has the shortest half-life of available TNFi and is administered subcutaneously. Several trials demonstrated the efficacy of ETN in early and stablished RA. The combination therapy with MTX demonstrated higher clinical response rates and less radiographic progression than ETN or MTX monotherapy. These improvements were sustained during open-label extension trials.

Adalimumab is a fully human monoclonal antibody binding TNF. The clinical efficacy of this compound in combination with methotrexate was shown to be superior than MTX alone in patients with early and stablish RA.

Certolizumab pegol is a pegylated, humanized anti-TNF Fab fragment. Its structure makes it different from other TNFi. CMZ demonstrated similar efficacy in achieving ACR disease activity measures as the other TNF inhibitors and similarly inhibits radiographic progression. Because it has minimal to no active placental transfer, analysis of pregnancy outcomes seems favorable to this drug regarding teratogenic effect and risk of fetal death.

Golimumab is a fully humanized monoclonal antibody that has demonstrated efficacy and safety in MTX naïve MTX inadequate response and in anti-TNF failure patients.

There is only one head to head trial that compares the efficacy and safety of two different TNF inhibitors. The 


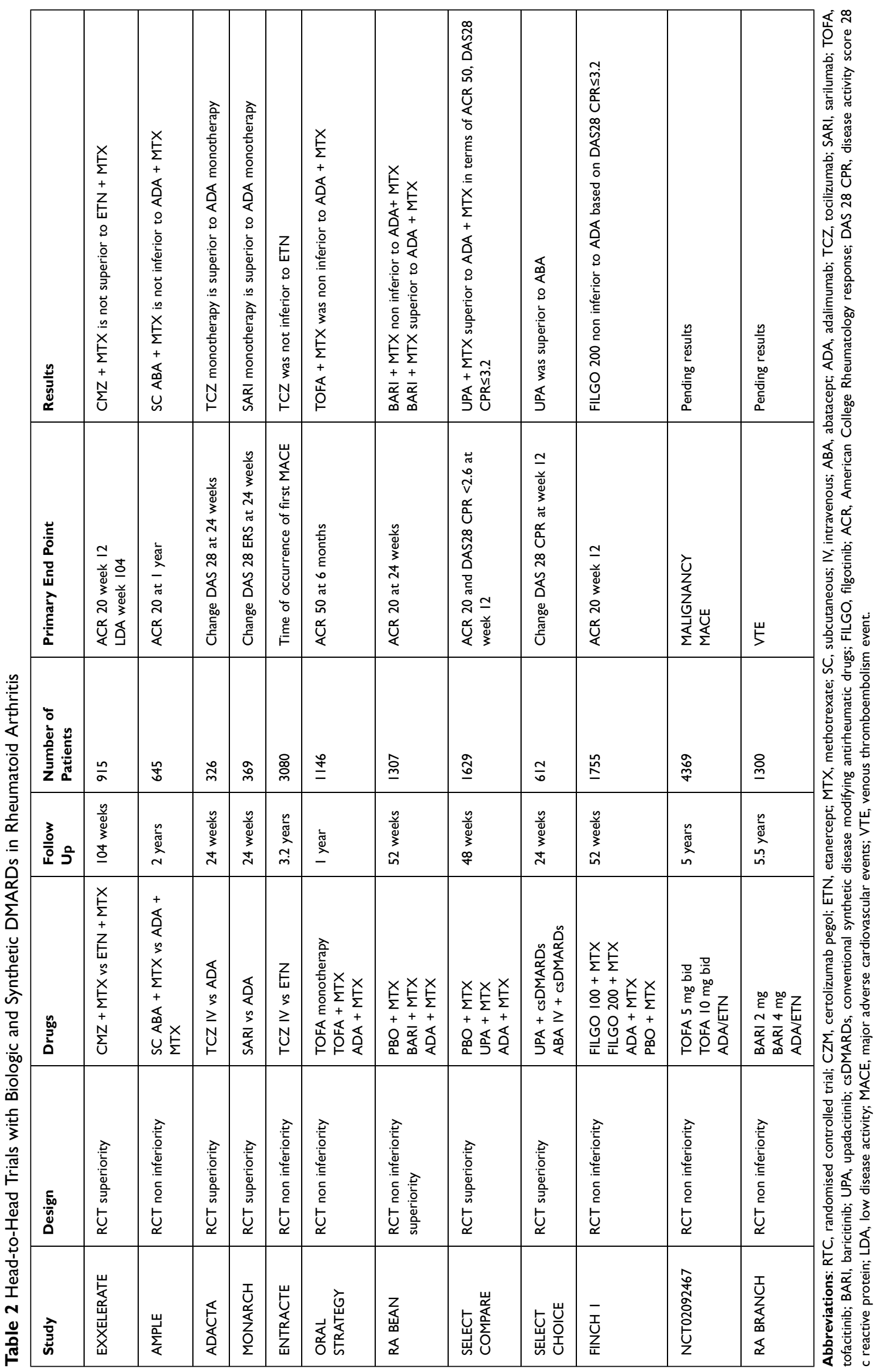


EXXELERATE study (Table 2), a superiority study, showed that certolizumab pegol plus methotrexate is not superior to adalimumab plus methotrexate (ACR20 response at week 12 $69 \%$ CZM vs $71 \%$ ADA; odds ratio 0.90 [95\% CI 0.67-1 20 ]; $\mathrm{p}=0 \cdot 467$ ). Comparisons based on indirect and retrospective data analyses have proven that the efficacy of anti-TNF seems broadly similar between the five drugs. However, some patients' characteristics could suggest that one TNF inhibitor is more favorable over the other. Data regarding safety also seem comparable between them. A meta-analysis of randomized clinical control trials of RA patients treated with anti-TNF demonstrated higher risk of serious infection (OR, $1.42 ; 95 \%$ confidence interval [CI], 1.13-1.78) and treatment discontinuation due to adverse events (OR, 1.23; 95\% CI, 1.06-1.43) compared with placebo and traditional diseasemodifying antirheumatic drug treatments. There is also a higher risk of reactivation of latent tuberculosis (TB) and other opportunistic infections. Monoclonal antibodies seem to have a higher risk of TB infection than etanercept. There have been reports of new episodes and exacerbations of central nervous system demyelinating disorders and lupus-like syndrome during anti-TNF therapy.

\section{T Cell Costimulatory Blocking (CD80/86)}

Abatacept is a fully human fusion protein that inhibits the second signal required for T-cell activation (by binding to CD80 and CD86 costimulatory antigens). It was first developed in EV formulation and later subcutaneously. Both treatment options showed comparable efficacy and safety in patients with RA. Abatacept reduces disease activity in MTX inadequate response patients. At 1 year, abatacept responses compared with placebo for ACR 20, 50 and 70 were $73.1 \%$ aba vs $39.7 \%$ pbo, $48.3 \%$ aba vs $18.2 \%$ pbo and $28.8 \%$ aba vs $6.1 \%$ pbo, respectively. Abatacept also produced significant clinical and functional benefits in patients who failed anti-TNF treatment. Several studies demonstrated the reduction of radiographic joint damage in patients treated with abatacept. The ATTEST study evaluated abatacept and infliximab vs placebo in RA patients with inadequate response to MTX. After one year, adverse events, serious infections and discontinuations due to $\mathrm{AE}$ were lower with abatacept than infliximab, showing a more acceptable safety and tolerability profile for this drug. The AMPLE trial (head to head comparing abatacept and adalimumab both combined with MTX) showed similar efficacy based on clinical functional and radiographic outcome. Even though the frequency of AE was similar in both groups, there were less discontinuations due to AEs and serious infections and fewer local injection site reactions with abatacept, favoring this drug (Table 2).

Like other biologics, serious infections were reported in patients with abatacept, but the frequency was low overall $(3.0 \%$ vs $1.9 \%$ in abatacept- versus placebotreated patients, respectively). There have been reports of acute infusion adverse effects $(9.8 \%$ vs $6.7 \%$ in the abatacept versus placebo groups, respectively) but were mostly mild-to-moderate in intensity. There is a label warning of abatacept and patients with chronic obstructive pulmonary disease because more frequent respiratory adverse events were reported in this population.

\section{Anti-Interleukin 6}

There are two interleukin 6 receptor antagonist (anti-IL6) drugs approved for the treatment of RA. Tocilizumab (TCZ) is a fully humanized monoclonal antibody directed against the IL-6 receptor that can be administrated intravenous or subcutaneous, and sarilumab, a human monoclonal antibody directed against the alpha subunit of the IL-6 receptor complex. Both drugs demonstrated to be effective for patients with inadequate response to csDMARDs (conventional synthetic disease modifying antirheumatic drugs) and to TNF inhibitors. The ACT-RAY study showed that there was no relevant superiority of TCZ + MTX compared to TCZ monotherapy regarding clinical and radiographic responses in MTX-IR patients. As a consequence, anti-IL6 have been recommended by EULAR guidelines in patients on monotherapy. Both drugs have been compared with an anti-TNF treatment in monotherapy. The MONARCH study, a double-blind head-to-head superiority trial, compared Sarilumab with adalimumab. Sarilumab was superior to adalimumab in terms of the change from baseline in DAS28-ESR ( -3.28 vs -2.20 ; $p<0.0001)$. The ADACTA trial showed the superiority of tocilizumab compared to adalimumab (DAS28 TCZ group (-3.3) vs ADA group $(-1.8)$, difference $-1.5,95 \%$ CI -1.8 to -1.1 ; $\mathrm{p}<0.0001$ ). Some side-effects of anti-IL6 inhibitors are more prevalent from the other available biologics like neutropenia, elevation of liver function tests (hepatic transaminases and bilirubin) and elevations of total cholesterol, triglycerides, and high-density lipoprotein levels. GI perforations have also been reported more frequently with IL6 inhibitors in the Rabbit and other registries. In the MONARCH and ADACTA trials, the incidence of infections was similar between anti IL6 inhibitors and ADA. In a head-to-head non-inferior trial of Etanercept vs Tocilizumab, there was no difference in the rate of cardiovascular events independently of the higher rate of cholesterol elevation with Tocilizumab (Table 2). 


\section{Rituximab (CD20)}

Rituximab is chimeric murine-human monoclonal antibody directed against CD20 that produces depletion of B cells. Its efficacy has been shown in patients who failed to respond to DMARDs. In the DANCER study significantly more patients who received rituximab in two $500 \mathrm{mg}$ or two $1000 \mathrm{mg}$ infusions with MTX achieved ACR 20 response rates at week 24 (55\% and 54\%, respectively), compared with placebo (28\%, $\mathrm{P}<0.001)$. Also, in patients with an inadequate response to anti-TNF therapies, a single course of rituximab (two $1000 \mathrm{mg}$ infusions 15 days apart) with concomitant MTX demonstrated significant improvements in disease activity. It seems that seropositive rheumatoid factors patients respond better to rituximab than seronegative patients. The most frequent adverse event with Rituximab is infusion reaction. Even though this drug produces a prolonged B cell depletion, the risk for serious infection was similar between the placebo and RXT groups. Fulminant reactivation of hepatitis B has been reported after rituximab treatment, the use of this drug in patients with hepatitis B positive serology is contraindicated. Progressive multifocal leukoencephalopathy, a very rare, but often fatal complication, has been described rarely in RA patients treated with RTX.

\section{Small Molecules: Janus Kinase Inhibitors}

The Janus Kinase inhibitors (JAKi) are the newest class of drug license for the treatment of RA. There are four different types of JAKs proteins: JAK1, JAK2, JAK3, and Tyk2 (tyrosine kinase) and so far, four different JAKs inhibitors are approved for the treatment of RA: Tofacitinib, Baricitinib, Upadacitinib and Filgotinib (penficitinib, a 5th one, is only approved in Japan and South Korea). All seem to share a similar efficacy and safety profile for patients with RA.

\section{Tofacitinib}

Tofacitinib is nonselective JAKi and was the first approved for the treatment of RA. Inhibits JAK1, JAK2, JAK3 and, to a lesser extent, TYK2. The Phase III tofacitinib trial program included 7 randomized controlled studies that demonstrated the efficacy, safety and prevention of structural damage in different populations of early and stablish RA patients.

The ORAL START was a MTX naïve trial that compared MTX to tofacitinib. The primary end point ACR 70 response rates were $25.5 \%$ in the $5 \mathrm{mg}$ twice a day (bid), $37.7 \%$ in the $10 \mathrm{mg}$ bid and $12 \%$ in the MTX $(\mathrm{P}<0.0001$ for both comparisons). Tofacitinib had significantly less radiographic progression than MTX (Sharp score 0.2 point in $5 \mathrm{mg}$ bid group, $<0.1$ point in $10 \mathrm{mg}$ bid group and 0.8 point in MTX group $\mathrm{P}<0.0001$ for both comparisons).

The ORAL Sync study evaluated the efficacy and safety of Tofacitinib in combination with csDMARDs. ACR 20 response rates at 6 months were $21.2 \%$ for tofacitinib $5 \mathrm{mg}$ bid compared to the combined placebo group $(\mathrm{P}<0.01)$.

The ORAL Scan trial compared in MTX-IR patients tofacitinib 5 and bid $10 \mathrm{mg}$ bid with placebo. The inhibition of structural damage by changes in total modified Sharp/van der Heijde from baseline was only statistically significant for the $10 \mathrm{mg}$ bid group compared to placebo ( 0.06 vs $0.47 \mathrm{P} \leq 0.05$, respectively).

The ORAL SOLO trial assessed the efficacy and safety of tofacitinib monotherapy in MTX-IR patients. Tofacitinib groups showed significantly higher percentage of ACR 20 response rates compared to placebo $(59.8 \%$ in the $5 \mathrm{mg}$ bid tofacitinib group and $65.7 \%$ in the $10 \mathrm{mg}$ bid tofacitinib group vs $26.7 \%$ in the combined placebo groups, $\mathrm{P}<0.001$ for both comparisons).

The ORAL STANDARD trial compared the efficacy and safety of tofacitinib with placebo and with Adalimumab (as a control) in MTX-IR patients. The study demonstrated that tofacitinib was significantly superior to placebo and was numerically similar to adalimumab in efficacy (ACR 20) response rates for tofacitinib $5 \mathrm{mg}$ bid $51.5 \%, 10 \mathrm{mg}$ bid $52.6 \%$, adalimumab $47.2 \%$ and placebo $28.3 \%$ ( $\mathrm{P}<0.001$ for all comparisons). This study was not a head-to-head trial to demonstrate superiority or non-inferiority between tofacitinib and adalimumab.

ORAL STEP compared the efficacy of tofacitinib with methotrexate in patients with an inadequate response to at least one prior TNF inhibitor. The primary end points demonstrated that tofacitinib plus methotrexate was superior than placebo in this treatment refractory population (ACR 20 $41.7 \%$ tofacitinib $5 \mathrm{mg}$ bid, $48.1 \%$ tofacitinib $10 \mathrm{mg}$ bid vs $24.4 \%$ placebo, $\mathrm{p}=0 \cdot 0024$ and $\mathrm{p}<0 \cdot 0001$, respectively). Also, there were statistically significant improvements in ACR 50 and 70 response rates, and PROs for tofacitinib groups.

ORAL Strategy, a phase $3 \mathrm{~b} / 4$ head to head, noninferiority trial assessed the efficacy of tofacitinib monotherapy, tofacitinib plus methotrexate, and adalimumab plus methotrexate in MTX-IR patients. ACR 50\% response rate (primary end point) was $38 \%$ for tofacitinib monotherapy, $46 \%$ for tofacitinib plus MTX and $44 \%$ for adalimumab plus MTX, demonstrating the non-inferiority of tofacitinib plus MTX vs Ada plus MTX. However, tofacitinib monotherapy was inconclusive to either combination (Table 2). 
Tofacitinib is approved in a dose regime of $5 \mathrm{mg}$ bid and in a 2016, an extended-release formulation of $11 \mathrm{mg}$ daily was approved later on.

\section{Baricitinib}

Baricitinib inhibits JAK1 and JAK2 and to a much lesser extent TYK2. Four randomized double-blind placebocontrolled phase III clinical trials assessed the efficacy of this drug as mono or in combination therapy in patients with RA. There is also a long extension study trial, for the patients that completed these pivotal trials. The five trials achieved the primary endpoint (ACR 20 improvement criteria) at week 12 and 24, and also major secondary endpoints (ACR 50 and 70, DAS28 response and patients reported outcomes) were accomplished by baricitinib vs placebo. RA BEGING evaluates baricitinib as monotherapy or combined with MTX compared to MTX monotherapy in patients who had received no or minimal (limited exposure) csDMARDs and who were naive to biologic DMARDs. Baricitinib monotherapy was superior to MTX monotherapy (primary endpoint), with a higher ACR20 response rate $(77 \%$ versus $62 \% ; P \leq 0.01)$. Similar results were observed for combination therapy. Radiographic progression showed a statistically significant reduction in structural damage for baricitinib plus MTX compared to MTX monotherapy, but not for the monotherapy.

RA BEACON assessed the efficacy in bDMARDs-IR patients, including at least one anti-TNF inhibitor. At week 12, ACR 20 responses (primary end point) were $55 \%$ for baricitinib $4 \mathrm{mg}$ and $49 \%$ for baricitinib $2 \mathrm{mg}$ compared with $27 \%$ for placebo group $(P<0.001)$.

RA BEAN included MTX IR patients. Study population was randomized to $\mathrm{PBO}$, baricitinib $4 \mathrm{mg}$ and Adalimumab $40 \mathrm{mg}$ on background MTX. Comparisons between baricitinib and adalimumab were controlled for multiplicity with respect to ACR20 response and change from baseline in DAS28-CPR at week 12. Baricitinib plus MTX was non-inferior to adalimumab plus MTX for the ACR20 response, with a margin of $12 \%$ ( $70 \%$ vs $61 \%$ for adalimumab), and was therefore considered to be significantly superior to adalimumab $(P=0.01)$. Radiographic progression was significantly lower for baricitinib compared with placebo (at 52 weeks change from baseline in mTSS was 0.71 vs 1.8 , respectively).

RA BUILD compared in MTX-IR patients baricitinib 2 and $4 \mathrm{mg}$ once a day to placebo. A statistically significant reduction in structural joint damage (radiographic outcome) from baseline to week 24 was observed for baricitinib 2 and $4 \mathrm{mg}$ compared with placebo.
The long extension trail RA_BEYOND included a substudy population for the assessment of a step-down dose strategy. Patients who were on baricitinib $4 \mathrm{mg}$ for at least 15 months and who had achieved sustained LDA or remission were re-randomized to continue with $4 \mathrm{mg}$ or stepping down to $2 \mathrm{mg}$. Most patients in both regimens (standard or step-down) were still in low disease activity or remission, but the stepdown group had statistically significant increase in tender and swollen joint count, physician global assessment, DAS28CRP, clinical disease activity index (CDAI), and SDAI scores. This demonstrated that the $4 \mathrm{mg}$ dose is the most effective and that stepping down strategy is a valid option but not for all patients.

\section{Upadacitinib}

Upadacitinib is selective for JAK1 74-fold over JAK2. Six global phase III randomized controlled clinical trials (SELECT phase III program) evaluated the efficacy and safety of upadacitinib covering different RA subpopulations. The approved dose for RA patients is $15 \mathrm{mg}$ once daily.

The SELECT NEXT study included active RA patients with an inadequate response to csDMARDs and the SELECT BEYOND trial patients with inadequate response or intolerance to bDMARDs. The SELECT MONOTHERAPY study showed the efficacy of upadacitinib monotherapy in clinical and functional outcomes vs methotrexate. In these studies, patients were randomized to upadacitinib 15 or $30 \mathrm{mg}$ or placebo for at least 12 weeks. Overall, results showed a rapid statistically significant improvement in the ACR20 response, and in the ACR50 and ACR70 responses with upadacitinib 15 and $30 \mathrm{mg}$. Several patients reported outcomes like quality of life, physical function, fatigue, and duration of morning stiffness were also significantly improved in upadacitinib arms.

The SELECT EARLY study compared the clinical efficacy of upadacitinib monotherapy vs MTX monotherapy, in MTX-naïve patients. Significantly, more patients receiving upadacitinib $15 \mathrm{mg}$ and $30 \mathrm{mg}$ vs MTX achieved both primary end points: ACR50 responses at week 12 $(52.1 \%$ and $56.4 \%$ vs $28.3 \%)$ and DAS28[CRP] $<2.6$ at week $24(48.3 \%$ and $50.0 \%$ vs $18.5 \%)$.

The SELECT COMPARE study evaluated the efficacy of upadacitinib as compared to PBO or adalimumab (ADA) in MTX IR patients. Patients were randomized to upadacitinib $15 \mathrm{mg}$, placebo, or ADA (40 mg every other week) while continuing to take a stable background dose of MTX. This study was designed and powered for superiority against placebo, noninferiority and superiority against ADA. Upadacitinib was superior to ADA based on the ACR50 
response rate ( $45 \%$ vs $29 \%$, respectively, $\mathrm{p} \leq 0.001$ ), change in pain severity score (mean change -32.1 upadacitinib group vs -25.6 ADA group; $\mathrm{P} \leq 0.001$ ), and change in the Health Assessment Questionnaire Disability Index (mean change -0.60 upadacitinib group vs -0.49 ADA group; $\mathrm{P} \leq 0.01$ ). At week 26, more patients receiving upadacitinib than those receiving $\mathrm{PBO}$ or ADA achieved low disease activity or remission $(\mathrm{P} \leq 0.001)$. The non-inferiority of upadacitinib compared to ADA was met for DAS28-CRP score of $\leq 3.2$ (45\% versus $29 \%$, respectively). The SELECT-CHOICE was the other head-to-head, double-blind study in bDMARD-IR patients comparing the efficacy and safety of upadacitinib $15 \mathrm{mg}$ to ABA IV, each in combination with stable background csDMARDs. The primary endpoint was the non-inferiority comparison of upadacitinib vs ABA in the change from baseline in DAS28(CRP) at Week 12. The results demonstrated that upadacitinib was non-inferior to ABA for the primary end point (change from baseline in DAS28(CRP) $\mathrm{P}<0.001$ ) and was superior to ABA for change from baseline in DAS28 (CRP) $(\mathrm{P}<0.001)$ and proportion of patients achieving DAS28(CRP) <2.6 remission $(\mathrm{P}<0.001)$ at Week 12 . A significant difference in the proportion of patients achieving DAS28(CRP) $<2.6$ was also maintained at Week 24 .

The impact of upadacitinib on structural joint damage was assessed during SELECT-EARLY and SELECT-COMPARE, showing in both studies that upadacitinib significantly reduced progression of joint damage as determined by significantly lower change from baseline in modified Total Sharp Score (mTSS) compared with MTX arms. No difference was seen compared to ADA in the mTSS.

\section{Filgotinib}

Filgotinib is a JAK1 selective is 30 fold more selective versus JAK2. The FINCH program includes four clinical phase III trials conducted also in different RA patient types that.

The FINCH 1 study included MTX-IR comparing: filgotinib $200 \mathrm{mg}$ or filgotinib $100 \mathrm{mg}$ once daily, subcutaneous adalimumab $40 \mathrm{mg}$ every 2 weeks, or matching placebo all with background MTX up to week 52. The primary end point was met by filgotinib in both doses compared to placebo at week 12 (ACR 20\%: 76.6\% filgotinib 200, 69.8\% filgotinib 100, 49.9\% placebo $\mathrm{P}<0.001$ and $70.8 \%$ ADA). Non-inferiority of filgotinib $200 \mathrm{mg}$ compared to ADA was met based on DAS28-CRP $\leq 3.2$ but the response between patients treated with filgotinib $100 \mathrm{mg}$ vs adalimumab was numerically similar (49.7\% filgotinib 200, 38.8\% filgotinib $100 \mathrm{mg}, 43.4 \%$ ADA). Radiographic progression measured by change from baseline in mTSS vs placebo at week 24 was significantly lower in filgotinib $200 \mathrm{mg}$ or $100 \mathrm{mg}$ vs placebo $(\mathrm{P}<0.001)$.

The FINCH 2 study evaluated the efficacy of filgotinib vs placebo in bDMARDs-IR patients. The primary end point, ACR 20 response rates at week 12 was 66\% (95\% CI, 58.0-74.0\%) and 57.5\% (95\% CI, 49.4-65.7\%) of patients with filgotinib $200 \mathrm{mg}$ and $100 \mathrm{mg}$, respectively, vs 31.1 (95\% CI, 23.3-38.9\%) for placebo (significant difference for both doses of filgotinib vs placebo $P<.001$ ).

The FINCH 3 trial included MTX naive, randomised to filgotinib $200 \mathrm{mg}$ once daily plus MTX, filgotinib $100 \mathrm{mg}$ plus MTX, filgotinib $200 \mathrm{mg}$ monotherapy and MTX $\leq$ $20 \mathrm{mg}$ weekly. At week 24, significantly more patients in the filgotinib $200 \mathrm{mg}+\operatorname{MTX}(81.0 \% ; P<0.001)$ and filgotinib $100 \mathrm{mg}+\operatorname{MTX}(80.2 \% ; P<0.05)$ arms achieved an ACR20 response compared to MTX monotherapy (71.4\%) (primary end point). Filgotinib $200 \mathrm{mg}$ monotherapy did not reach a significant difference compared to MTX on ACR20, although it did on ACR 50/70 at week 24. There was less radiographic progression as measured by change in mTSS from baseline at week 52 in patients receiving filgotinib 100/200 mg plus MTX and filgotinib $200 \mathrm{mg}$ monotherapy vs MTX monotherapy.

The FINCH 4 is a study that is evaluating the longterm safety and tolerability of filgotinib in participants who have completed one of the parent studies of filgotinib in RA. The study is still active and partial results are expected soon.

The safety data from JAK inhibitors comes from the clinical development programs and post-marketing surveillance. All JAKi produce changes in laboratory parameters that may differ between the drugs in relation of the selectivity for each JAK. There have been changes in blood cell counts (risk of lymphopenia), haemoglobin levels, liver transaminase, creatine kinase, cholesterol and creatine. A higher risk of infection was reported with $\mathrm{JAKi}$, and the most common serious infection reported for tofacitinib and baricitinib was pneumonia. There is difference between JAKi and other bDMARDs regarding the risk of herpes zoster infection, which is higher with these drugs and is most marked in Japanese and Korean ethnicity patients. Concerns have been raised for a potential risk of thromboembolic events (pulmonary embolism and deep vein thrombosis) with these drugs that are still under evaluation. 
Table 3 Up to Date 15 Biosimilars Have Been Approved by the FDA for Rheumatic Diseases

\begin{tabular}{|c|c|c|c|}
\hline Comercial Name & Compound Name & Date Aproved & Reference Product \\
\hline labni & Rituximab-arx & December 2020 & Rituxan(rituximab) \\
\hline Hulio & Adalimumab-fkjp & July 2020 & Humira (adalimumab) \\
\hline Avsola & Infliximab-axxq & December 2019 & Remicade(infliximab) \\
\hline Abrilada & Adalimumab-afzb & November 2019 & Humira (adalimumab) \\
\hline Hadlima & Adalimumab-bwwd & July 2019 & Humira (adalimumab) \\
\hline Ruxience & Rituximab-pvvr & July 2019 & Rituxan (rituximab) \\
\hline Eticovo & Etanecerpt-ykro & April 2019 & Enbrel (etanecerpt) \\
\hline Truxima & Rituximab-abbs & November 2018 & Rituxan (rituximab) \\
\hline Hyrimoz & Adalimumab-adaz & October 2018 & Humira (adalimumab) \\
\hline Ixifi & Infliximab-qbtx & December 2017 & Remicade (infliximab) \\
\hline Cyltezo & Adalimumab-adbm & December2017 & Humira (adalimumab) \\
\hline Renflexis & Infliximab-abda & Mayo2017 & Remicade (infliximab) \\
\hline Amjevita & Adalimumab-atto & September 2016 & Humira (adalimumab) \\
\hline Erelzi & Etanecerpt-szzi & August 2016 & Enbrel (etanecerpt) \\
\hline Inflectra & Infliximab-dyyb & April 2016 & Remicade (infliximab) \\
\hline
\end{tabular}

\section{Biosimilars}

A biosimilar is an agent that presents a similar molecular structure of the active substance of an already approved agent, the reference product and is intended to be used in the same way as the reference product. It must have similar biological activity and quality characteristics and should have no significant safety nor efficacy differences. To get a biosimilar to be approved, it must undergo a thorough full development process that involves a series of comparability exercises to establish biosimilarity to the reference product and at least one randomized controlled trial (Tables 3 and 4). The aim of biosimilarity clinical trials is not to establish efficacy per se, which has already been established in clinical trials conducted with the reference product, but to demonstrate equivalent clinical performance of the biosimilar in relation to the reference product. The same quality manufacturing standards that apply to the original biologic also apply to the biosimilar. When biosimilarity is demonstrated in one indication, this can be extrapolated to other approved indications of the reference product.

The approval of biosimilars can help the health care systems worldwide to make substantial savings. If patients receiving a reference biological product are switched to biosimilars, and if biological-naive patients are started on biosimilars rather than reference products, it could save economic resources as long as the cost is much lower. Thus, improving the access of the population to biologic treatment in case it is needed and provide an earlier usage.

\section{Emerging Therapies}

There are up to date some promising molecules with different mechanism of actions in the pipeline to be approved.

Otilimab is a human monoclonal antibody that inhibits granulocyte-macrophage colony-stimulating factor (GM$\mathrm{CSF}$, a key driver in immune-mediated inflammatory conditions. A phase $2 \mathrm{~b}$, dose-ranging, multicenter, placebo-controlled study (Baroque study) was done. A total 222 patients who were receiving stable methotrexate were randomly assigned to six different groups subcutaneous placebo or otilimab $22.5 \mathrm{mg}, 45 \mathrm{mg}, 90 \mathrm{mg}, 135 \mathrm{mg}$, or $180 \mathrm{mg}$, plus methotrexate, once weekly for 5 weeks, then every other week until week 50 . Otilimab plus methotrexate was well tolerated and, despite not achieving the primary endpoint of DAS28-CRP remission, there were improvements compared with placebo in disease activity scores. Patients reported significant improvement in pain and physical function, supporting further clinical development of otilimab in 
Table 4 Adding to This List the EMA Has Approved 16 More Biosimilars

\begin{tabular}{|l|l|l|}
\hline Commercial Name & Date Aproved & Reference Product \\
\hline Remsima & September 2013 & Rituximab \\
\hline Iraldi & September 2013 & Infliximab \\
\hline Nepexto & May 2015 & Etanecerpt \\
\hline Ritemvia & July 2017 & Rituximab \\
\hline Blitzima & July 2017 & Rituximab \\
\hline Halimatoz & July 2018 & Adalimumab \\
\hline Idacio & April 2019 & Adalimumab \\
\hline Asparity & February 2020 & Adalimumab \\
\hline Zessly & May 2018 & Infliximab \\
\hline Hyrimoz & May 2016 & Adalimumab \\
\hline Flixabi & May 2016 & Infliximab \\
\hline Ruxience & April 2020 & Rituximab \\
\hline Kromaya & April 2019 & Adalimumab \\
\hline Riximyo & June 2017 & Rituximab \\
\hline Solymbic & March 2017 & Adalimumab \\
\hline Rixathon & June 2017 & Rituximab \\
\hline Benepali & Eary 2016 & Etanecerpt \\
\hline
\end{tabular}

rheumatoid arthritis. The phase III clinical program (named "ContRAst") is ongoing. It compares otilimab against placebo (ContRAst 1) and against two treatments with different modes of actions: tofacitinib (ContRAst 2) and sarilumab (ContRAst 3). The program also enrolls a broad range of difficult-to-treat patients who have had an inadequate response to or have been unable to tolerate currently available treatments. Patients who complete the pivotal studies may be eligible to participate in a long-term extension study to further evaluate the efficacy and safety of otilimab for up to 4 years.

Olokizumab is a monoclonal antibody that targets interleukin (IL) 6 . There are currently 4 clinical trials to evaluate the treatment of moderate to severe active rheumatoid arthritis (RA) in adults for whom methotrexate is inadequate or had presented inadequate response to antiTNF alpha blockers. The CREDO 1, CREDO2 and CREDO 3 (core studies) evaluate the efficacy and safety of different regimens of subcutaneous Olokizumab compared to placebo (CREDO 1 and 3 ) or adalimumab (CREDO 2) CREDO 4 evaluates the long-term safety, tolerability and efficacy of two dosing regimens of Olokizumab (OKZ), in subjects with Rheumatoid Arthritis (RA) who previously completed 24 weeks of blinded treatment in one of the core studies.

ABX464 is a small molecule that produces a specific and selective induction of miR-124 in immune cells. miR124 is a crucial modulator of inflammation and innate immunity that could provide therapeutic restitution of physiological pathways lost in inflammatory diseases. The Phase 2a ongoing study, ABX464-301, investigates the safety and tolerability of ABX464 in combination with methotrexate in patients with moderate-to-severe active RA. Patients enrolled in the study had an inadequate response to methotrexate or/and to one or more antitumor necrosis factor alpha (TNF $\alpha$ ) therapies. Patients who complete the ABX464-301 trial, have the possibility to roll over into a Phase 2a open-label study, ABX464302 , aiming at the evaluation of the one-year safety and efficacy of ABX464 as maintenance therapy in RA.

Iscalimab (CFZ533) is a fully human, aglycosilated nondepleted monoclonal antibody that blocks CD154-CD40 pathway activation that is being developed as an immunosuppressive agent. The CD40-CD154 costimulatory pathway is essential for the generation of $\mathrm{T}$ cell-dependent antibody responses (TDAR), germinal center (GC) formation, and memory $\mathrm{B}$ cell differentiation. In macrophages and dendritic cells, it regulates their activation and differentiation as well as antigen presentation to $\mathrm{T}$ cells. Due to its mechanism of action, Iscalimab shows to be a promising therapy in transplant rejection and autoimmune diseases. The first Phase1 randomized, double-blind, placebocontrolled, parallel-group, 2-part study clinical trial was conducted between January 2013 and February 2017, to asses pharmacokinetics, pharmacodynamics, safety, and tolerability of ascending intravenous doses of iscalimab. In this trial, there was a cohort of RA between 18 and 65 years old. Iscalimab showed to be safe and well tolerated at single doses up to $30 \mathrm{mg} / \mathrm{kg} \mathrm{IV}$ with no evidence of increased risk of infection or thromboembolic complications. There are ongoing phase 2 studies in Graves' disease, liver transplant rejection, lupus nephritis, myasthenia gravis, renal transplant rejection, Sjogren's syndrome, systemic lupus erythematosus and type 1 diabetes mellitus.

\section{Conclusion}

The better understanding of the pathogenesis of RA has allowed the development of a great number of effective therapies for the treatment of this disease. Even though the 
menu is wide, there is still a lack of reliable tools for predicting which patients will respond better to a given drug. The increasing numbers of head-to-head trials is essential in order to answer the question of which therapy is more effective and safer for each individual patient. Also, more trials dealing with tapering or stopping therapy are still needed to help optimize the use of the existing drugs. Remission of LDA persistence remains a goal to achieve.

Despite the advances in therapies, the most important strategy is the early diagnosis and treatment, and the frequent assessments of disease activity with adjustments in therapy for achieving clinical remission or low disease activity in most patients.

\section{Disclosure}

Dr Eduardo Mysler reports grants, personal fees from Pfizer, Roche, grants from AbbVie, GSK, Aztra Zeneca, Sandoz, Lilly, Sanofi, grants from Novartis, BMS, grants from Janssen, Amgen, outside the submitted work. The authors report no other conflicts of interest in this work.

\section{References}

1. Smolen JS, Aletaha D, McInees LB. Rheumatoid arthritis. Lancet. 2016;388(10055):2023-2038. doi:10.1016/S0140-6736(16)30173-8

2. Smolen JS, Landewé RBM, Bijlsma JWJ, et al. EULAR recommendations for the management of rheumatoid arthritis with synthetic and biological disease-modifying antirheumatic drugs: 2019 update. Ann Rheum Dis. 2020;79(6):685-699. doi:10.1136/annrheumdis-2019216655

3. Smolen JS, Breedveld FC, Burmester GR, et al. Treating rheumatoid arthritis to target: 2014 update of the recommendations of an international task force. Ann Rheum Dis. 2016;75(1):3-15. doi:10.1136/ annrheumdis-2015-207524

4. Jasvinder AS, Kenneth GS, Louis Bridges JR, et al. 2015 American college of rheumatology guideline for the treatment of rheumatoid arthritis. Arthritis Care Res. 2016;68(1):1-25. doi:10.1002/acr.22783

5. van Vollenhoven RF, Geborek P, Forslind K, et al. Conventional combination treatment versus biological treatment in methotrexate-refractory early rheumatoid arthritis: 2 years follow-up of the randomised, non-blinded, parallel-group Swefot trial. Lancet. 2012;379(9827):1712-1720. doi:10.1016/S0140-6736(12)60027-0

6. Katchamart W, Trudeau J, Phumethum V, et al. Efficacy and toxicity of methotrexate (MTX) monotherapy versus MTX combination therapy with non-biological disease-modifying antirheumatic drugs in rheumatoid arthritis: a systematic review and meta-analysis. Ann Rheum Dis. 2009;68(7):1105-1112. doi:10.1136/ard.2008.099861

7. Kavanaugh A, van Vollenhoven RF, Fleischmann R, et al. Testing treat-to-target outcomes with initial methotrexate monotherapy compared with initial tumor necrosis factor inhibitor (adalimumab) plus methotrexate in early rheumatoid arthritis. Ann Rheum Dis. 2018;77 (2):289-292. doi:10.1136/annrheumdis-2017-211871

8. Radner H, Aletaha D. Anti-TNF in the rheumatoid arthritis: an overview. Wien Med Wochenschr. 2015;165(1-2):2-9. doi:10.1007/ s10354-015-0344-y

9. Feldmann M. Development of anti-TNF therapy for rheumatoid arthritis. Nat Rev Immunol. 2002;2(5):364-371. doi:10.1038/nri802
10. Maini R, St Clair EW, Breedveld F, et al. Infliximab (chimeric anti-tumor necrosis factor alpha monoclonal antibody) versus placebo in rheumatoid arthritis patients receiving concomitant methotrexate: a randomised phase III trial. ATTRACT Study Group. Lancet. 1999;354(9194):1932-1939. doi:10.1016/S0140-6736(99)05246-0

11. St Clair EW, van der Heijde DM, Smolen JS, et al. Combination of infliximab and methotrexate therapy for early rheumatoid arthritis: a randomised, controlled trial. Arthritis Rheum. 2004;50 (11):3432-3443. doi:10.1002/art.20568

12. Lipsky PE, van der Heijde DM, St Clair EW, et al. Infliximab and methotrexate in the treatment of rheumatoid arthritis. $N$ Engl J Med. 2000;343(22):1594-1602. doi:10.1056/NEJM200011303432202

13. Bathon JM, Martin RW, Fleischmann RM, et al. A comparison of etanercept and methotrexate in patients with early rheumatoid arthritis. N Engl J Med. 2000;343(22):1586-1593. doi:10.1056/ NEJM200011303432201

14. Emery P, Breedveld FC, Hall S, et al. Comparison of methotrexate monotherapy with a combination of methotrexate and etanercept in active, early, moderate to severe rheumatoid arthritis (COMET): a randomised, double-blind, parallel treatment trial. Lancet. 2008;372(9636):375-382. doi:10.1016/S0140-6736(08)61000-4

15. van der Heijde D, Klareskog L, Rodriguez-Valverde V, et al. Comparison of etanercept and methotrexate, alone and combined, in the treatment of rheumatoid arthritis: two-year clinical and radiographic results from the TEMPO Study, a double-blind, randomized trial. Arthritis Rheum. 2006;54(4):1063-1074. doi:10.1002/art.21655

16. Moreland LW, Weinblatt ME, Keystone EC, et al. Etanercept treatment in adults with established rheumatoid arthritis: 7 years of clinical experience. $J$ Rheumatol. 2006;33(5):854-861.

17. Breedveld FC, Weisman MH, Kavanaugh AF, et al. The PREMIER Study: a multicenter, randomized, double-blind clinical trial of combination therapy with adalimumab plus methotrexate versus methotrexate alone or adalimumab alone in patients with early, aggressive rheumatoid arthritis who had not had previous methotrexate treatment. Arthritis Rheum. 2006;54(1):26-37. doi:10.1002/art.21519

18. Keystone EC, Kavanaugh AF, Sharp JT, et al. Radiographic, clinical, and functional outcomes of treatment with adalimumab (a human anti-tumor necrosis factor monoclonal antibody) in patients with active rheumatoid arthritis receiving concomitant methotrexate therapy: a randomized, placebo-controlled, 52-week trial. Arthritis Rheum. 2004;50(5):1400-1411. doi:10.1002/art.20217

19. Keystone E, Heijde D, Mason D Jr, et al. Certolizumab pegol plus methotrexate is significantly more effective than placebo plus methotrexate in active rheumatoid arthritis: findings of a Fifty-Two-Week, Phase III, Multicenter, Randomized, Double-Blind, Placebo-Controlled, Parallel-Group Study. Arthritis Rheum. 2008;58 (11):3319-3329. doi:10.1002/art.23964

20. Fleischmann R, Vencovsky J, van Vollenhoven RF, et al. Efficacy and safety of certolizumab pegol monotherapy every 4 weeks in patients with rheumatoid arthritis failing previous disease-modifying antirheumatic therapy: the FAST4WARD Study. Ann Rheum Dis. 2009;68 (6):805-811. doi:10.1136/ard.2008.099291

21. Clowse MEB, Scheuerle AE, Chambers C, et al. Pregnancy outcomes after exposure to certolizumab pegol: updated results from a pharmacovigilance safety database. Arthritis Rheum. 2018;70 (9):1399-1407. doi:10.1002/art.40508

22. Emery P, Fleischmann RM, Strusberg I, et al. Efficacy and safety of subcutaneous golimumab in methotrexate-naive patients with rheumatoid arthritis: five-year results of a randomized clinical trial. Arthritis Care Res. 2016;68(6):744-752. doi:10.1002/acr.22759

23. Keystone EC, Genovese MC, Klareskog L, et al. Golimumab, a human antibody to tumor necrosis factor alpha given by monthly subcutaneous injections, in active rheumatoid arthritis despite methotrexate therapy: the GO-FORWARD Study. Ann Rheum Dis. 2009;68 (6):789-796. doi:10.1136/ard.2008.099010 
24. Smolen JS, Kay J, Doyle MK, et al. Golimumab in patients with active rheumatoid arthritis after treatment with tumor necrosis factor alpha inhibitors (GO-AFTER Study): a multicentre, randomised, double-blind, placebo-controlled, phase III trial. Lancet. 2009;374 (9685):210-221. doi:10.1016/S0140-6736(09)60506-7

25. Smolen JS, Burmester GR, Combe B, et al. Head-to-head comparison of certolizumab pegol versus adalimumab in rheumatoid arthritis: 2-year efficacy and safety results from the randomised EXXELERATE Study. Lancet. 2016;388(10061):2763-2774. doi:10.1016/S0140-6736(16)31651-8

26. Michaud TL, Rho YH, Shamliyan T, et al. The comparative safety of tumor necrosis factor inhibitors in rheumatoid arthritis: a meta-analysis update of 44 trials. Am $J$ Med. 2014;127 (12):1208-1232.

27. Liao H, Zhong Z, Liu Z, Zou X. Comparison of the risk of infections in different anti-TNF agents: a meta-analysis. Int $J$ Rheum Dis. 2017;20(2):161-168. doi:10.1111/1756-185X.12970

28. Fleischmann R, Yocum D. Does safety make a difference in selecting the right TNF antagonist? Arthritis Res Ther. 2004;6(Supp12):S12-8. doi: $10.1186 /$ ar 995

29. Genovese MC, Covarrubias A, Leon G, et al. Subcutaneous abatacept versus intravenous abatacept: a phase IIIb noninferiority study in patients with an inadequate response to methotrexate. Arthritis Rheum. 2011;63(10):2854-2864. doi:10.1002/art.30463

30. Kremer JM, Genant HK, Moreland LW, et al. Effects of abatacept in patients with methotrexate-resistant active rheumatoid arthritis: a randomized trial. Ann Intern Med. 2006;144(12):865-876. doi:10.7326/0003-4819-144-12-200606200-00003

31. Genovese MC, Becker JC, Schiff M, et al. Abatacept for rheumatoid arthritis refractory to tumor necrosis factor alpha inhibition. $N$ Engl $J$ Med. 2005;353(11):1114-1123. doi:10.1056/NEJMoa050524

32. Kremer JM, Genant HK, Moreland LW, et al. Results of a two-year followup study of patients with rheumatoid arthritis who received a combination of abatacept and methotrexate. Arthritis Rheum. 2008;58(4):953-963. doi:10.1002/art.23397

33. Genant HK, Peterfy CG, Westhovens R, et al. Abatacept inhibits progression of structural damage in rheumatoid arthritis: results from the long-term extension of the AIM trial. Ann Rheum Dis. 2008;67(8):1084-1089. doi:10.1136/ard.2007.085084

34. Schiff M, Keiserman M, Codding C, et al. Efficacy and safety of abatacept or infliximab vs placebo in ATTEST: a phase III, multi-centre, randomised, double-blind, placebo-controlled study in patients with rheumatoid arthritis and an inadequate response to methotrexate. Ann Rheum Dis. 2008;67(8):1096-1103. doi:10.1136/ ard.2007.080002

35. Schiff M, Weinblatt ME, Valente R, et al. Head-to-head comparison of subcutaneous abatacept versus adalimumab for rheumatoid arthritis: two-year efficacy and safety findings from AMPLE trial. Ann Rheum Dis. 2014;73(1):86-94. doi:10.1136/annrheumdis-2013203843

36. Sibilia J, Westhovens R. Safety of T-cell co-stimulation modulation with abatacept in patients with rheumatoid arthritis. Clin Exp Rheumatol. 2007;25(5 Suppl 46):S46-56.

37. Weinblatt M, Combe B, Covucci A, et al. Safety of the selective costimulation modulator abatacept in rheumatoid arthritis patients receiving background biologic and nonbiologic disease-modifying antirheumatic drugs: a One-Year Randomized, Placebo-Controlled Study. Arthritis Rheum. 2006;54(9):2807-2816. doi:10.1002/ art. 22070

38. Genovese MC, McKay JD, Nasonov EL, et al. Interleukin-6 receptor inhibition with tocilizumab reduces disease activity in rheumatoid arthritis with inadequate response to disease-modifying antirheumatic drugs: the tocilizumab in combination with traditional disease-modifying antirheumatic drug therapy study. Arthritis Rheum. 2008;58(10):2968-2980. doi:10.1002/art.23940
39. Huizinga TW, Fleischmann RM, Jasson M, et al. Sarilumab, a fully human monoclonal antibody against IL-6R $\alpha$ in patients with rheumatoid arthritis and an inadequate response to methotrexate: efficacy and safety results from the randomised SARIL-RA-MOBILITY Part A trial. Ann Rheum Dis. 2014;73(9):1626-1634. doi:10.1136/ annrheumdis-2013-204405

40. Emery P, Keystone E, Tony HP, et al. IL-6 receptor inhibition with tocilizumab improves treatment outcomes in patients with rheumatoid arthritis refractory to anti-tumor necrosis factor biologicals: results from a 24-week multicentre randomised placebo-controlled trial. Ann Rheum Dis. 2008;67(11):1516-1523. doi:10.1136/ $\operatorname{ard} .2008 .092932$

41. Fleischmann R, van Adelsberg J, Lin Y, et al. Sarilumab and nonbiologic disease-modifying antirheumatic drugs in patients with active rheumatoid arthritis and inadequate response or intolerance to tumor necrosis factor inhibitors. Arthritis Rheum. 2017;69 (2):277-290. doi:10.1002/art.39944

42. Dougados M, Kissel K, Sheeran T, et al. Adding tocilizumab or switching to tocilizumab monotherapy in methotrexate inadequate responders: 24-week symptomatic and structural results of a 2-year randomised controlled strategy trial in rheumatoid arthritis (ACT-RAY). Ann Rheum Dis. 2013;72(1):43-50. doi:10.1136/ annrheumdis-2011-201282

43. Burmester GR, Lin Y, Patel R, et al. Efficacy and safety of sarilumab monotherapy versus adalimumab monotherapy for the treatment of patients with active rheumatoid arthritis (MONARCH): a randomised, double-blind, parallel-group phase III trial. Ann Rheum Dis. 2017;76 (5):840-847. doi:10.1136/annrheumdis-2016-210310

44. Gabay C, Emery P, van Vollenhoven R, et al. Tocilizumab monotherapy versus adalimumab monotherapy for treatment of rheumatoid arthritis (ADACTA): a randomised, double-blind, controlled phase 4 trial. Lancet. 2013;381(9877):1541-1550. doi:10.1016/S01406736(13)60250-0

45. Barbulescu A, Delcoigne B, Askling J, Frisell T. Gastrointestinal perforations in patients with rheumatoid arthritis treated with biological disease-modifying antirheumatic drugs in Sweden: a Nationwide Cohort Study. RMD Open. 2020;6(2):e001201. doi:10.1136/rmdopen-2020-001201

46. Strangfeld A, Richter A, Siegmund B, et al. Risk for lower intestinal perforations in patients with rheumatoid arthritis treated with tocilizumab in comparison to treatment with other biologic or conventional synthetic DMARDs. Ann Rheum Dis. 2017;76(3):504-510. doi:10.1136/annrheumdis-2016-209773

47. Giles JT, Sattar N, Gabriel S, et al. Cardiovascular safety of tocilizumab versus etanercept in rheumatoid arthritis: a randomized controlled trial. Arthritis Rheum. 2020;72(1):31-40. doi:10.1002/ art.41095

48. Emery P, Fleischmann R, Filipowicz-Sosnowska A, et al. The efficacy and safety of rituximab in patients with active rheumatoid arthritis despite methotrexate treatment: results of a phase IIB randomized, double-blind, placebo-controlled, dose-ranging trial. Arthritis Rheum. 2006;54(5):1390-1400. doi:10.1002/art.21778

49. Cohen SB, Emery P, Greenwald MW, et al. Rituximab for rheumatoid arthritis refractory to anti-tumor necrosis factor therapy: results of a multicenter, randomized, double-blind, placebo-controlled, phase III trial evaluating primary efficacy and safety at twenty-four weeks. Arthritis Rheum. 2006;54(9):2793-2806. doi:10.1002/art.22025

50. Chatzidionysiou K, Lie E, Nasonov E, et al. Highest clinical effectiveness of rituximab in autoantibody-positive patients with rheumatoid arthritis and in those for whom no more than one previous TNF antagonist has failed: pooled data from 10 European registries. Ann Rheum Dis. 2011;70(9):1575-1580. doi:10.1136/ard.2010.148759

51. Hernández-Cruz B, García-Arias M, Ariza Ariza R, et al. Rituximab in rheumatoid arthritis: a systematic review of efficacy and safety. Reumatol Clin. 2011;7(5):314-322. doi:10.1016/j.reuma.2011.03.004 
52. Smolen JS, Keystone EC, Emery P, et al. Consensus statement on the use of rituximab in patients with rheumatoid arthritis. Ann Rheum Dis. 2007;66(2):143-150. doi:10.1136/ard.2006.061002

53. Fleischmann RM. Progressive multifocal leukoencephalopathy following rituximab treatment in a patient with rheumatoid arthritis. Arthritis Rheum. 2009;60(11):3225-3228. doi:10.1002/art.24906

54. Taylor PC. Clinical efficacy of launched JAK inhibitors in rheumatoid arthritis. Rheumatology (Oxford). 2019;58(Suppl 1):i17-i26. doi:10.1093/rheumatology/key225

55. Fleischmann R. Tofacitinib in the treatment of active rheumatoid arthritis in adults. Immunotherapy. 2018;10(1):39-56. doi:10.2217/ imt-2017-0118

56. Lee EB, Fleischmann R, Hall S, et al. Tofacitinib versus methotrexate in rheumatoid arthritis. $N$ Engl J Med. 2014;370(25):2377-2386. doi:10.1056/NEJMoa1310476

57. Kremer J, Li ZG, Hall S, et al. Tofacitinib in combination with nonbiologic disease-modifying antirheumatic drugs in patients with active rheumatoid arthritis: a randomized trial. Ann Intern Med. 2013;159(4):253-261. doi:10.7326/0003-4819-159-4-20130820000006

58. van der Heijde D, Tanaka Y, Fleischmann R, et al. Tofacitinib (CP-690,550) in patients with rheumatoid arthritis receiving methotrexate: twelve-month data from a twenty-four-month phase III Randomized Radiographic Study. Arthritis Rheum. 2013;65 (3):559-570. doi:10.1002/art.37816

59. Fleischmann R, Kremer J, Cush J, et al. Placebo-controlled trial of tofacitinib monotherapy in rheumatoid arthritis. $N$ Engl J Med. 2012;367(6):495-507. doi:10.1056/NEJMoa1109071

60. van Vollenhoven RF, Fleischmann R, Cohen S, et al. Tofacitinib or adalimumab versus placebo in rheumatoid arthritis. $N$ Engl J Med. 2012;367(6):508-519. doi:10.1056/NEJMoa1112072

61. Burmester GR, Blanco R, Charles-Schoeman C, et al. Tofacitinib (CP-690,550) in combination with methotrexate in patients with active rheumatoid arthritis with an inadequate response to tumor necrosis factor inhibitors: a randomised phase 3 trial. Lancet. 2013;381(9865):451-460. doi:10.1016/S0140-6736(12)61424-X

62. Fleischmann R, Mysler E, Hall S, et al. Efficacy and safety of tofacitinib monotherapy, tofacitinib with methotrexate, and adalimumab with methotrexate in patients with rheumatoid arthritis (ORAL Strategy): a phase $3 \mathrm{~b} / 4$, double-blind, head-to-head, randomised controlled trial. Lancet. 2017;390(10093):457-468. doi:10.1016/S01406736(17)31618-5

63. Fleischmann R, Schiff M, van der Heijde D, et al. Baricitinib, methotrexate, or combination in patients with rheumatoid arthritis and no or limited prior disease-modifying antirheumatic drug treatment. Arthritis Rheum. 2017;69(3):506-517. doi:10.1002/ art.39953

64. Genovese M, Kremer J, Zamani O, et al. OP0029 baricitinib, an oral janus kinase (JAK)1/JAK2 inhibitor, in patients with active rheumatoid arthritis (RA) and an inadequate response to TNF Inhibitors: results of the phase 3 RA-Beacon Study. Ann Rheum Dis. 2015;74:75-76. doi:10.1136/annrheumdis-2015-eular.1427

65. Taylor P, Keystone E, van der Heijde D, et al. Baricitinib versus placebo or adalimumab in patients with active rheumatoid arthritis (RA) and an inadequate response to background methotrexate therapy: results of a Phase 3 Study. Arthritis Rheum. 2015;67:26-30.

66. Dougados M, van der Heijde D, Chen YC, et al. Baricitinib in patients with inadequate response or intolerance to conventional synthetic DMARDs: results from the RA-BUILD Study. Ann Rheum Dis. 2017;76(1):88-95. doi:10.1136/annrheumdis-2016210094

67. Takeuchi T, Genovese M, Xie L, et al. OP0228 baricitinib dose step down following disease control in patients with rheumatoid arthritis. Ann Rheum Dis. 2016;75(Suppl 2):144. doi:10.1136/annrheumdis2016-eular. 1610
68. Bechman K, Yates M, Galloway JB. The new entries in the therapeutic armamentarium: the small molecule JAK inhibitors. Pharmacol Res. 2019;147:104392. doi:10.1016/j.phrs.2019.104392

69. Burmester GR, Kremer JM, Van den Bosch F. Safety and efficacy of upadacitinib in patients with rheumatoid arthritis and inadequate response to conventional synthetic disease-modifying anti rheumatic drugs (SELECT-NEXT): a randomised, double-blind, placebo-controlled phase 3 trial. Lancet. 2018;391 (10139):2503-2512. doi:10.1016/S0140-6736(18)31115-2

70. Genovese MC, Fleischmann R, Combe B, et al. Safety and efficacy of upadacitinib in patients with active rheumatoid arthritis refractory to biologic disease-modifying anti-rheumatic drugs (SELECT-BEYOND): a double-blind, randomised controlled phase 3 trial. Lancet. 2018;391(10139):2513-2524. doi:10.1016/S01406736(18)31116-4

71. Smolen JS, Pangan AL, Emery P, et al. Upadacitinib as monotherapy in patients with active rheumatoid arthritis and inadequate response to methotrexate (SELECT-MONOTHERAPY): a Randomised, Placebo-Controlled, Double-Blind Phase 3 Study. Lancet. 2019;393 (10188):2303-2311. doi:10.1016/S0140-6736(19)30419-2

72. van Vollenhoven R, Takeuchi T, Pangan AL, et al. A phase 3 , randomized, controlled trial comparing upadacitinib monotherapy to MTX monotherapy in MTX-naive patients with active rheumatoid arthritis (abstract). Arthritis Rheum. 2018;70(suppl 10):891.

73. Fleischmann RM, Genovese MC, Enejosa JV, et al. Safety and effectiveness of upadacitinib or adalimumab plus methotrexate in patients with rheumatoid arthritis over 48 weeks with switch to alternate therapy in patients with insufficient response. Ann Rheum Dis. 2019;78(11):1454-1462. doi:10.1136/annrheumdis-2019215764

74. Rubbert-Roth A, Enejosa J, Pangan A, et al. Efficacy and safety of upadacitinib versus abatacept in patients with active rheumatoid arthritis and prior inadequate response or intolerance to biologic disease-modifying anti-rheumatic drugs (select-choice): a double-blind, randomized controlled phase 3 trial. Ann Rheum Dis. 2020;79:1015-1016.

75. Combe B, Kivitz A, Tanaka Y, et al. Efficacy and safety of filgotinib for patients with rheumatoid arthritis with inadequate response to methotrexate: finch 1 52-week results. Ann Rheum Dis. 2020;79 (Suppl 1):320-321. doi:10.1136/annrheumdis-2020-eular.276

76. Genovese MC, Kalunian K, Gottenberg JE, et al. Effect of filgotinib vs placebo on clinical response in patients with moderate to severe rheumatoid arthritis refractory to disease-modifying antirheumatic drug therapy: the FINCH 2 randomized clinical trial. JAMA. 2019;322(4):315-325. doi:10.1001/jama.2019.9055

77. Westhovens R, Rigby W, Van der Heijde D, et al. Efficacy and safety of filgotinib in methotrexate-naive patients with rheumatoid arthritis: finch 3 52-week results. Ann Rheum Dis. 2020;79(Suppl 1):1019-1020. doi:10.1136/annrheumdis-2020-eular.277

78. Long term extension study to assess the safety and efficacy of filgotinib in adults with rheumatoid arthritis (FINCH 4). U. S National library of Medicine, clinical trials. Available from: https://clinicaltrials.gov/ct2/show/NCT03025308. Accessed July 18, 2020.

79. Harigai M. Growing evidence of the safety of JAK inhibitors in patients with rheumatoid arthritis. Rheumatology (Oxford). 2019;58 (Suppl 1):i34-i42. doi:10.1093/rheumatology/key287

80. Cohen SB, Tanaka Y, Mariette X, et al. Long-term safety of tofacitinib for the treatment of rheumatoid arthritis up to 8.5 years: integrated analysis of data from the global clinical trials. Ann Rheum Dis. 2017;76(7):1253-1262. doi:10.1136/annrheumdis-2016-210457

81. Genovese MC, Smolen JS, Takeuchi T, et al. Safety profile of baricitinib for the treatment of rheumatoid arthritis up to 5.5 years: an updated integrated safety analysis (Abstract 511). Arthritis Rheum. 2017;69:Abstract 511. 
82. Scott IC, Hider SL, Scott DL. Thromboembolism with Janus Kinase (JAK) inhibitors for rheumatoid arthritis: how real is the risk? Drug Saf. 2018;41(7):645-653. doi:10.1007/s40264-018-0651-5

83. Phase $3 \mathrm{~B} / 4$ randomized safety endpoint study of 2 doses of tofacitinib in comparison to a tumor necrosis factor (TNF) inhibitor in subjects with rheumatoid arthritis. Available from: https:/www.clin icaltrials.gov/ct2/show/NCT02092467?term=NCT02092467\&draw= 2\&rank=1. Accessed February 14, 2021.

84. A study of baricitinib in participants with rheumatoid arthritis (RA-BRANCH). Available from: https:/www.clinicaltrials.gov/ct2/ show/NCT04086745?term $=$ NCT04086745\&draw $=2 \&$ rank $=1$.

Accessed February 14, 2021.

85. European Medicines Agency. Guideline on similar biological medicinal products containing biotechnology-derived proteins as active substance: non-clinical and clinical issues. December, 2014.

86. US Food and Drug Administration (FDA), Center for Drug Evaluation and Research (CDER), Center for Biologics Evaluation and Research (CBER). Scientific considerations in demonstrating biosimilarity to a reference product: guidance for industry. April, 2015.

87. Smolen JS, Goncalves J, Quinn M, et al. Era of biosimilars in rheumatology: reshaping the healthcare environment. RMD Open. 2019;5(1):e000900. doi:10.1136/rmdopen-2019-000900
88. Bucley CD. Efficacy, patient-reported outcomes, and safety of the anti-granulocyte macrophage colony-stimulating factor antibody otilimab (GSK3196165) in patients with rheumatoid arthritis: a Randomised, Phase 2b, Dose-Ranging Study. Lancet. 2020;2: E677-E688.

89. Genovese MC, Fleischmann R, Furst D, et al. Efficacy and safety of olokizumab in patients with rheumatoid arthritis with an inadequate response to TNF inhibitor therapy: outcomes of a Randomised Phase IIb Study. Ann Rheum Dis. 2014;73(9):1607-1615. doi:10.1136/ annrheumdis-2013-204760

90. Phase 3 results for olokizumab in RA patients. The-rheumatologist. org. March 3, 2020.

91. Tazi J, Begon-Pescia C, Campos N, Apolit C, Garcel A, Scherrer D. Specific and selective induction of miR-124 in immune cells by the quinoline ABX464: a transformative therapy for inflammatory diseases. Drug Discov Today. 2021.

92. Espié P, He Y, Koo P, et al. First-inhuman clinical trial to assess pharmacokinetics, pharmacodynamics, safety, and tolerability of iscalimab, an anti-CD40 monoclonal antibody. Am J Transplant. 2020;20 (2):463-473. doi:10.1111/ajt.15661
Open Access Rheumatology: Research and Reviews

\section{Publish your work in this journal}

Open Access Rheumatology Research and Reviews is an international, peer-reviewed, open access journal publishing original research, reports, editorials, reviews and commentaries on all aspects of clinical and experimental rheumatology in the clinic and laboratory including the following topics: Pathology, pathophysiology of rheumatological diseases; Investigation, treatment and management

\section{Dovepress}

of rheumatological diseases; Clinical trials and novel pharmacological approaches for the treatment of rheumatological disorders. The manuscript management system is completely online and includes a very quick and fair peer-review system, which is all easy to use. Visit http://www.dovepress.com/testimonials.php to read real quotes from published authors. 